\title{
Research on SWOT Analysis and Strategy of Education Live Broadcasting
}

\author{
Jitao Yao \\ College of Vocational Technology \\ Xi'an University of Architecture and Technology \\ Xi'an, China 710055
}

\author{
Yao Meng \\ College of Vocational Technology \\ Xi'an University of Architecture and Technology \\ Xi'an, China 710055
}

\begin{abstract}
Educational live broadcasting breaks the traditional form of education. And it also is an endogenous force that promotes the development of "Internet plus education". The article uses the SWOT analysis method to comprehensively interpret the advantages, disadvantages, opportunities and threats in the development of education live broadcasting, and proposes effective strategies that are beneficial to the development of live education.
\end{abstract}

Keywords—education live broadcasting; SWOT analysis; development; strategy

\section{INTRODUCTION}

Since the "China Webcast First Year" in 2016, the live broadcasting has been covered from entertainment and game fields to news, sports, tourism, education and other fields due to the characteristics of immediacy and interactivity. For a time, people's horizons have been filling with various kinds of "live broadcasting". The live broadcasting platforms represented by "huajiao", "yingke", and "douyu" have developed rapidly. However, in order to compete for audiences, each live broadcasting platform caters to the fun of popular entertainment. And the atmosphere of the entire industry is increasingly impetuous with novel and exciting content and forms [1]. In addition, the education live broadcasting has short time of the development. The research literature on education live broadcasting is rare. According to the data of CNKI, the author uses "educational live broadcasting" as a key word. The search results are as the following. From 2005 to 2015, the number of documents in each year is a single digit, and online related education literature is more about online learning models such as MOOC, SPOC, etc. The number of documents related to "educational live broadcasting" has gradually increased since 2016. The related research has not yet formed a large scale. With the rapid development of the Internet, the education live broadcasting becomes more and more popular. With the development trend in the past two years, its popularity will continue to increase. Therefore, based on the research on current development of education live broadcasting, the author analyzes and evaluates the strengths and weakness, opportunities and threats of the education live broadcasting respectively through the SWOT analysis method, and proposes corresponding development strategy recommendations. It is of reference significance for future development of China's "Internet + education".

\section{SWOT ANALYSIS OF EDUCATION LIVE BROADCASTING}

SWOT, also known as Superiority Weakness Opportunity Threats, was proposed by H. Weihrich, a professor of management at the University of San Francisco, in the early 1980s. It is a strategic option favored by the western business community. The SWOT method is based on surveys. It uses systematic analysis ideas to analyze the internal resources and external environment of the organization. And then, it would judge the strengths and weakness, opportunities and threats of external environment. In the end, it can determine the best plan for the development of the organization. Among them, "S" and "W" are internal conditions, referring to the strengths and weakness of the organization's development. "O" and "T" are external environments, referring to the opportunities and threats faced during the development of the organization. At present, the SWOT analysis method is gradually well-known and widely used in various fields of society. And it has become an effective analysis method for organizations or institutions to formulate practical strategic decisions [2].

\section{A. Analysis of the Strengths of Education Live Broadcasting}

The so-called strength (S) refers to the conditions or factors that live broadcasting has to contribute to educational development. This paper breaks through the traditional thinking paradigm of "problem" and explores the characteristics of the development of education live broadcasting based on the unique thinking style of "strengths", which will help increase understanding of education development and change. First, education live broadcasting has the advantage of resource sharing. The Internet-based teaching broadcasting can bring together outstanding teachers from all over the country. The scholars in various places can have the master courses. And in the case of good communication equipment and network signals, a course can accommodate tens of thousands of students. It improves the overall teaching level. Also, it would be conducive to promoting education fair. Second, it can save the cost. There is no need for live broadcasting equipment in 
network broadcasting teaching. Most of them use live capture cards for live streaming. And it can be viewed on a computer or mobile phone. Moreover, the education live broadcasting breaks through the limitations of time and place. Students can learn courses through the Internet at any time and place, avoid spending time on the back and forth of the tutoring classes, and spend more time and energy on learning. It not only saves teaching costs, but also saves time costs. Thirdly, the education live broadcasting has immediacy. The teaching content and teaching methods are relatively novel. The curriculum setting starts from the student's position. For the immediate question of students or some of the latest forms of examination and content changes, the teacher can immediately answer the students' questions through the live broadcasting platform. The education live broadcasting breaks through the geographical and time constraints, realizes the instant interaction of online education, reduces the cost of learning and communication, and can effectively realize the mutual fusion of relationalism and neoconstructivism in learning in the Internet age [3]. Fourth, education is highly interactive. In the direct broadcasting room, students can communicate with teachers through online comment. Also, the students can ask teachers about the contents of the lecture through real-time comments. They can also interact with students in the direct broadcasting room to create a group or communicate with each other. It avoids the deficiencies of one-way teaching, improves students' enthusiasm for learning. The students would participate in the course. And the effectiveness of course would be better. Fifth, the main body of education broadcasting evaluation has diversity. In the current education methods, examinations always account for the largest proportion of the overall evaluation, while other comprehensive evaluations account for a very small proportion. The MOOCs that had launched online education boom did not focus on the unique evaluation methods of online learning. The evaluation model that focuses on examinations and tests as the main evaluation method is very similar to the existing evaluation model of Chinese universities [4]. In the teaching mode of education live broadcasting, the roles and status of teachers and students have changed. The appraisers have changed from students to teachers, while the evaluation subjects have changed from teachers to students. Students can evaluate teacher's teaching effectiveness based on their own learning effects. The students can also communicate with teachers in a timely manner on the platform. According to the feedback, teachers can adjust their teaching content or methods to adapt to the needs of students. It would effectively improve the quality of teaching.

\section{B. Analysis of Weaknesses of Education Live Broadcasting}

The so-called weakness (W) refers to the unfavorable factors that hinder the development of education. First, the overall level of interaction is not high. The education live broadcasting realizes the real-time interaction of online education. The students can communicate with teachers in a timely manner. However, viewing from the recent situation, the number of students in a popular live broadcasting course can be as high as 10,000 . In this case, teachers can only selectively answer students' questions, and cannot take every student into consideration. It is difficult to achieve effective interaction in the teaching process. Over time, it will reduce students' efficiency and motivation in attending classes. In addition, most of the students who are in the education broadcasting have the course informally. As a result, students often study in a free state. The learning process cannot be effectively supervised. And the effect cannot be verified. It is difficult to judge the actual teaching effect. The overall level of interaction is low. Second, the quality of teachers is uneven. In the case where everyone can make live broadcasting teaching, the teaching resources are abundant and the choice of students is wider. However, there is no uniform assessment standard for the current teachers' level of education live broadcasting. Many online celebrity teachers have become popular through students' pursuits and hot discussions on the Internet. There is no definite information to indicate the educational background of these teachers. And we can't judge their true teaching quality and professional level. As a result, students will not be able to make effective judgments facing with numerous choices. Third, the degree of interaction between students and teachers is low. Interaction between students and teachers is a kind of unique classroom culture of traditional classrooms. It is a process of group learning [5]. Through classroom discussion and exchange of ideas, students can enhance their thinking ability and cognitive structure. Also, they can feel the classroom competition produced by interaction and enhance classroom participation. Studying in a strong learning environment, internal mechanisms also make the students have certain psychological implications. Thereby, the students would continue learning and sustain this behavior. However, in the live-broadcasting teaching process, students can send comments through the Internet to interact in real time. In the real environment, they are in a single learning state. There is no mutual influence among students and reality communication. And the degree of interaction between students and teachers is low.

\section{Analysis on External Opportunities of Education Live Broadcasting}

The so-called opportunity refers to the favorable opportunity provided by the changes in the external environment and situation for the education live broadcasting. The first is the support of the "Internet+" policy. As the country vigorously promotes the "Internet+" strategy, various industries have made the response positively. It has accelerated the exchange and integration of industries. And it has promoted optimization, reconstruction and innovation of the industry. Also, it has formed a new type of "Internet+" ecosystem. The further development of the education live broadcasting creates a stable platform to achieve multiple and in-depth developments of online education [6]. The second is the opportunity for the development of "mobile learning" According to relevant reports, the number of online education users in China reached 138 million by December 2016, an increase of 27.5 million over the end of 2015. The annual growth rate is $25.0 \%$. At the same time, the usage rate of online education user also increased by $2.7 \%$ from 2015 . And China's online education industry can be said to have 
risen steadily and maintained a relatively high growth speed [7]. About $56 \%$ of users said that they were willing to pay for online education APP in mobile phone. These data all indicate that "mobile learning" has provided a new opportunity for the development of education live broadcasting.

\section{Analysis on External Threats of Education Live Broadcasting}

The so-called threat refers to the challenge or threat to the development of education live broadcasting due to changes in the external environment and situation. First, the relevant national policies are not perfect. In 2015, the State Council issued the "Guiding Opinions on Actively Promoting the "Internet+" Initiative". It has promoted the concept of "Internet+" to the national development strategy, further expanded the market scale of online education, and greatly increased the number of users [8]. However, excessive attention and growth trends have also put a lot of pressure on the sound development of education live broadcasting. And the related policy on education live broadcasting has not been perfected. There is no clear standard for the market business model and sustainable development model. Some corporate financing depends on business models. And some corporate financing relies on the scale of users. This makes the healthy development of education live broadcasting have greater challenge. Second, there is no standardized educational live broadcasting model. According to the research, most people nowadays believe that education live broadcasting is the same as "Internet+" education. There are relatively successful educational live broadcasting platforms such as "HJenglish" and "Edutainment". As a whole, there is no systematic, influential and mature education live broadcasting model in China.

\section{THE DEVELOPMENT STRATEGY OF EDUCATION LIVE BROADCASTING}

According to the analysis of the characteristics and problems of the education live broadcasting, the education live broadcasting has its admirable advantages. Also, it needs to be improved. Therefore, in order to better support online education and achieve long-term development with live education broadcasting, people can adopt the following strategies.

\section{A. To Improve Learning Support Service System}

From the experience of previous online education development, the establishment of a sound and effective learning support service system is an important guarantee for the efficiency and quality of distance learning [7]. At present, there is no systematic learning support service system for education live broadcasting. Many education live broadcasting platforms only focus on students' online participation. Therefore, education live broadcasting can learn from the previous experience of online learning support services. And they can establish a complete learning support service system from network service support, curriculum recommendation and course participation.

\section{B. To Establish an Effective Evaluation System}

Currently, teachers in the education live broadcasting industry mainly rely on student rewards as their main means of fame and fortune. It cannot intuitively reflect the professional qualities and teaching level of teachers. The evaluation system is an integral part of the current development of education live broadcasting. Double evaluation methods of ratings and comments are used for evaluation. The "double-evaluation models" of expert evaluation and student evaluation are quoted. The diversified evaluation model makes the evaluation effect more objective and authentic. It will fully exert the orientation and incentive function of evaluation.

\section{The Selection of Excellent Live Broadcasting Teacher}

The education live broadcasting course needs the immediacy of teaching. And the teachers must have the proficiency of the lecture content in the process of live broadcasting. Also, they should maintain the fluency of the language and the agility of thinking. In addition, teachers must have teaching advantages and features to enhance the popularity of live broadcasting. Therefore, teachers in the era of education live broadcasting need to have professional qualities and professional capabilities. Also, they need to keep up with the trend of the times and attract students' attention. Therefore, the selection of teachers with high quality is the key. With the support of live broadcasting technology, the live broadcasting teachers deliver the teaching service to any place where it is needed. It not only realizes the sharing of high-quality educational resources, but also enhances its own influence. This is particularly valuable for areas where educational resources are lacking.

\section{Effective Integration with Traditional Classroom}

Looking back at online education in the past, the development of online education is rapid and unstoppable. And it cannot replace traditional classrooms. Therefore, the combination of education live broadcasting and traditional classroom is one of the ways to have long-term development. Combining education live broadcasting with traditional classrooms, we should take traditional classrooms as the main way. The education live broadcasting would be assistant. The students should have uniform learning in traditional classroom. The teachers would give individual resolution or refine lectures on the live broadcasting platform. The teachers should adopt online and offline teaching mode. Students can learn basic knowledge. Also, it would meet their individual needs.

\section{CONCLUSION}

In the "Internet+" era, the emergence of education live broadcasting is an inevitable outcome of the development of the times. Therefore, the "live broadcasting + education" learning method based on the "rigid" needs of learner's individualized learning is in line with the service concept of "learning as the center". It is a new learning method that supports the learning metaphor of technology. It can bring more diverse and convenient interaction information for learners, which represents the development direction of 
future learning. At the same time, the emergence of education live broadcasting has brought new opportunities and breakthroughs to online education. And it has also brought new problems and challenges. Therefore, we should take strength (S) and opportunities (O) of education live broadcasting, overcome its weakness (W) and threats (T), and allow education live broadcasting to better assist the development of education and help online education.

\section{REFERENCES}

[1] Zheng Xurong, Huang Chuanlin, Xu Chaoyue, Yu Jingyang. An Analysis of the Live Broadcasting Platform Based on "Internet Plus"[J]. Value Engineering, 2018, 37(04): 165-166. 郑旭蓉,黄川林, 徐超越, 于敬洋. 基于“互联网+”的教育直播平台探析 [J]. 价值工 程, 2018,37(04):165-166.

[2] Dong Xiangjun, Chen Weihua. SWOT Analysis and Strategy Exploration of Poverty Alleviation of Vocational Education [J]. China Vocational and Technical Education, 2017(23):55-59. 董香君, 陈维华.职业教育精准扶贫的 SWOT 分析及其策略探究 [J].中国职 业技术教育,2017(23):55-59.

[3] Liu Jia. "Live Broadcasting + Education": The New Forms and Values of "Internet + Learning" [J]. Journal of Distance Education, 2017, 35(1):52-59. 刘佳. “直播+教育”: 互联网+”学习的新形式与 价值探究[J].远程教育杂志, 2017,35(1):52-59.

[4] Zheng Qinhua, Chen Li, Lin Shiyuan. Internet + Education: Construction and Development of MOOCs in China [M]. Beijing: Publishing House of Electronics Industry, 2016. 郑勤华,陈丽,林世员. 互联网+教育: 中国 MOOCs 建设与发展 [M]. 北京: 电子工业出版 社,2016.

[5] Hao Chun'e. Changes in China's Education Patterns Triggered by the Education Live Broadcasting [J]. China Education Informatization, 2016(23):28-29. 郝春娥.教育直播引发的中国教育形态变革[J].中 国教育信息化,2016(23):28-29.

[6] Gao Pei, Liu Xuewei, Liu Fengjuan. SWOT Analysis and Development Strategy of Online Education [J]. China Education Informatization, 2017(16):1-4. 高沛,刘学伟,刘风娟.在线教育的 SWOT 分析及发展战略探究[J].中国教育信息化,2017(16):1-4.

[7] Xue Dianyun. The online education live broadcast in 2017 is gradually heating up, and training institutions are specialized and refined [EB/OL] (2017-02-28)[2017-04-15]. http://www.toutiao.com/i6391980326524027393/.html. 学点云.2017 年在线教育直播逐渐升温, 培训机构专而精成主流 [EB/OL]. (2017-02-28)[2017-04-15]. http://www.toutiao.com/i6391980326524027393/.html.

[8] Chen Li. "Innovation Essence and Reform Trend of "Internet + Education" [J]. Journal of Distance Education, 2016, 34(04): 3-8. 陈 丽. “互联网+教育”的创新本质与变革趋势 [J]. 远程教育杂 志,2016,34(04):3-8. 